\title{
Research on the Mode of Postgraduates' Innovative Education in the "Internet+" Era
}

\author{
Lu Gan ${ }^{1, \text { a }}$, Rensheng $\mathrm{He}^{2^{\star}}$ and Lu Liü, b \\ ${ }^{1}$ School of Physics and Microelectronics, Hunan University, Changsha 410000, China; \\ ${ }^{2}$ School of Physics and Microelectronics, Hunan University, Changsha 410000, China. \\ aganlu07@163.com, *hdwlhrs@hnu.edu.cn, bnaisilu@163.com
}

Keywords: "Internet+", postgraduates, innovative education.

\begin{abstract}
The strategy of "Internet +" not only provides opportunities to postgraduate innovative education, but also indicates the direction of reformation. Actually, there exists a certain gap between the orientation of educational reform which pointed by the "Internet + " and the development of postgraduate innovative education. "Internet + postgraduate innovative education" is not an online education but an idea of reforming. The previous development mode of postgraduate education no longer meets the need of the "Internet +" era. Therefore, it is essential for us to explore and reform the innovative education mode. By integrating the "Internet +" into the four segments of postgraduate education: course teaching, academic guidance and communication, practice of scientific research and innovative ability evaluation, we can find out a new mode of postgraduate innovative education. Hope to provide reference for the research of postgraduate innovative ability training in our country.
\end{abstract}

\section{Introduction}

On the twelfth session of the National People's Congress of the three meeting held in March 5, 2015, Premier Li Keqiang first proposed the formulation of the "Internet +" action plan. The same year in July 1st promulgated the "guiding opinions of the State Council on promoting 'Internet +' action". Aiming at the field of education, the paper pointed out that the Internet as the infrastructure and innovative elements to explore new ways of education service supply.

Generally speaking, "Internet +" is the "Internet + various traditional industries", this is not a simple combination of both, but a deep integration of the Internet and traditional industries. It innovates the organizational mode, service mode and teaching mode of education by using the Internet as infrastructure and an innovative element, hence to build a new educational eco-system in the digital age [1].

\section{Status quo of innovation ability of postgraduates in China}

In recent years, our country's higher education has become more and more popular. Statistics show that, the enrollment scale of postgraduates from 128,500 in 2000 soared to 538,200 in 2010, increased by 4 times in ten years, average annual growth rate reached 32\%. In 2015, our country has 645,100 postgraduates, and the total number of postgraduates has reached 1,911,400.

Along with the increase in the number, the various problems in postgraduate education gradually reveal. The contradiction between quantity and quality of training is becoming more and more acute. It's an indisputable fact that postgraduate training quality is not high, especially the lack of innovative ability. More and more scholars began to pay attention to this problem, and called for the optimization of postgraduate innovative education.

\section{The integration of "Internet +" and postgraduate innovative education}

The "Internet +" has brought substantial changes for some industries. Compared with other industries, the development of education has been in a state of slow. So far, there is no a more powerful "Internet + postgraduate innovative education" mode, but this does not affect our imagination and exploration. 
To be sure, "Internet +" will bring profound changes to education. We can explore the "Internet +" with postgraduate innovative education from the following aspects.

\subsection{Course teaching}

Curriculum participation is the basic factor that affects the innovation ability of postgraduate students [2]. According to Sternberg's view, if a person wants to make innovation in one area, he needs to know enough about the field. Learners can reserve a solid foundation of professional knowledge, and know the professional frontier by participating in the course of study. The degree of curriculum participation directly decides how much knowledge can be acquired. The two main factors that influence the students' curriculum participation are course content and teaching mode. At present, it is not conducive for postgraduates to master the frontier knowledge because of the obsolete course content. It is difficult for teachers to teach students in accordance with their aptitude according to students' personality by traditional classroom teaching mode.

The Internet can absorb vast amount of knowledge and information quickly in a short period of time, because of its strong storage and interactive advantages [3]. It can make up for the lack of course content. Relying on the Internet we can effectively improve teaching by using $\mathrm{O} 2 \mathrm{O}$ (online to offline) mode, mixing online teaching and classroom teaching (cf. Fig. 1, below). With the help of the Internet, postgraduates can enjoy the quality teaching resources, and master the most cutting-edge research in the field at any time. Students can learn on Internet independently before class, then go to classroom with questions and thinking. In classroom teaching, the teacher will explain key points and difficult points, and develop interactive teaching. After class, students can also conduct online course to review again, to deepen understanding and consolidation. This mode makes full use of the advantages of online teaching, let the classroom become an important channel of knowledge impartation. At the same time, it also strengthens the interaction between teachers and students, students and students in the classroom, can be better to explore knowledge, think, interaction and practice.

Beyond that, with the continuous development of big data technology and learning analysis technology, we can store and record all the learning behavior characteristic data of learners by learning platform. According to these data, teachers can accurately grasp the students' learning situation and personal characteristics. On the one hand, teachers can adjust the teaching, on the other hand can teach students in accordance of their aptitude.

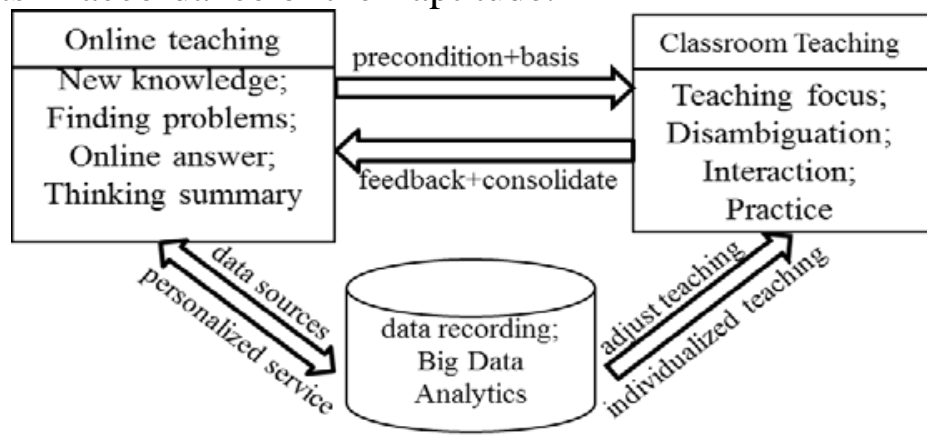

Fig. 1 O2O teaching mode

\subsection{Academic guidance and communication}

Academic guidance is an important factor influences the postgraduate innovative ability. At present, the domestic colleges and universities basically implement one mentor responsibility system. A postgraduate is only in charge of one mentor. A mentor is solely responsible for the ideological education, academic research and other aspects of the postgraduate. The advantage of this system is that it can establish a close relationship between mentors and students. The weakness is that once the relationship between mentors and students has problems, or because of the mentor's ability, energy and other reasons can not get effective guidance, it is not easy for postgraduates to change the mentor or to get guidance from other means. The communication between the students also contributes to the improvement of innovative ability. Because of these limiting factors, such as the number of personnel, research direction or other elements, many scientific research teams lack effective communication.

The emergence of the Internet, breaking the shackles of a lot of restrictions. We could not only 
share the material resources, but also share the human resources. We can learn from the successful case of "Internet + medical industry", "Good doctor online" Web, to create a "mentor online" web for postgraduates (cf. Fig. 2, below). The platform includes the following several modules: individual archives, peer communication, questions posting, mentors consulting. Good mentors come from the national and even global are introduced to the platform, they can carry out academic guidance for postgraduates. Graduates can have a personal account just by registering and completing personal information. Individual archives platform can be synchronous updated with the data of individual learning characteristics based on big data analysis, also can publish their own learning insights and thinking summaries. It is facilitated for online mentors to know about the situation of postgraduates fully. Peer exchange platform is a communication and mutual aid bridge between graduate students. Post questions platform and mentor consulting platform are dedicated to the exchange between mentors and postgraduates. Postgraduates can not only release the problem on the platform, waiting for the mentors who have the relevant research experience to answer and guide, but also search for the right mentors to seek targeted advice according to the mentor's label. After the guidance, mentors can be evaluated by postgraduates.

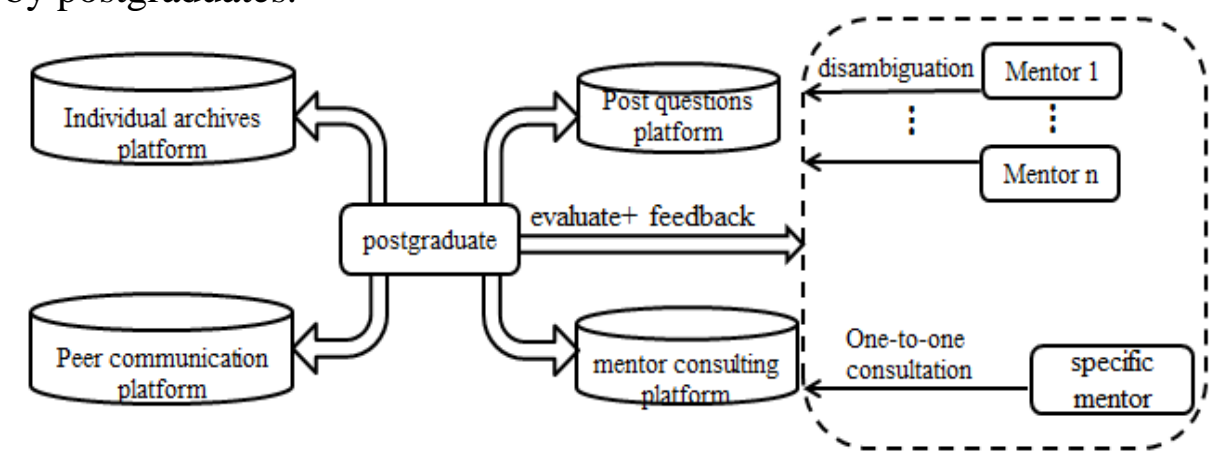

Fig. 2 "mentor online” platform

\subsection{Practice of scientific research}

Participate in scientific research is the key factor to realize the qualitative change of innovative ability. Scientific researches includes participating in the project, experimental researches etc. The author once did a small survey, about $30 \%$ of the 70 postgraduates were never involved in the projects. Another scholar also found that by a research, only 37\% of the 386 postgraduates often participate in the projects, most postgraduates rarely participate in research during school. Projects have become a scarce resource [4]. There are a lot of postgraduates, especially science and engineering students, can not carry out their experimental study successfully, because the school laboratory equipment is not perfect or the experiment is dangerous.

Using virtual reality technology, we can create a "virtual research community" for postgraduates, which similar to the virtual world in the game. In this community, students can produce immersive feelings by using the corresponding devices which allow students to interact, perceive and manipulate objects in the virtual world [5]. The postgraduate can recruit companions who have the common research interest to form a scientific research team, without be restricted by the region. They can declare the project together, and carry on the project research in the virtual community. These projects could guide the reality. Meanwhile, postgraduates can carry out a variety of experiments in the virtual community, no longer be subjected to the limitations of experimental equipment and experimental properties.

\subsection{Innovative ability evaluation}

For a long time, there is no a clear standard for the evaluation of postgraduate innovative ability. The innovative ability of postgraduates is a concept that can not be measured accurately. Many domestic scholars often choose the quantity and quality of scientific research results to be the index to evaluate the postgraduates' innovative ability. The consequence of such a single evaluation guide is that we only focus on scientific research results. It is a difficult problem that how to evaluate the postgraduates' innovative ability in all directions and multi perspectives, and the evaluation results can also in turn guide the improvement of the level of innovative ability effectively. 
The big data analysis technology has brought hope to the problem. In addition to reference to the scientific research, we can also record the students' online learning situation, evaluation feedback, exchange activities, virtual community practice and so on, with the help of the Internet. And then put these into the evaluation basis, so we can collect the postgraduates' information in all directions, multi angles and multi channels. Using data analysis technology, we can make a scientific, comprehensive and systematic evaluation of postgraduate innovative ability. These results can be directly feed back to the postgraduate through the Internet, and make targeted guidance to improve the innovative ability, so as to achieve the purpose of effective evaluation.

\section{Summary}

The dialectical materialism of Marx doctrine tells us that there are two sides of things. "Internet + " is no exception. It is a double-edged sword, when we use it to cut off all the thorns on the road of graduate innovative education, we also need to prevent certain things hurt ourselves. Guard against a series of problems that may arise, for instance, how to screen out the high quality network teaching resources from the massive resources, how to solve the problem of students' self-control, how to avoid the relationship between teachers and students become indifferent because of the Internet, etc.

In short, in order to achieve the remarkable development of graduate innovative education, and complete the goal of delivering high level talents for our country. It is necessary to according to the characteristics of postgraduate innovative education, and seize the opportunity to seek change, try and explore actively, and finally find out the development path in the "Internet +" era.

\section{Acknowledgments}

This study was supported by the Chinese Society of Academic Degrees and Graduate Education (Grants No.2015Y0403). The corresponding author is Rensheng He.

\section{References}

[1] Li Chen, Shiyuan Lin, Qinhua Zheng, Opportunities and Challenges of Chinese Distance Education in the "Internet +" Era, Modern Distance Education Research. 139(2016)3-10.

[2] Hong Zhu, Wenli Li, Zujing Zuo, The Status of Graduate Students' Creativity and Its Influence Mechanism, Journal of Higher Education. 32(2011)74-82.

[3] Yan Zhang, On the Concept and Mode of "Internet Plus Education”, China Higher Education Research. 2(2016)70-73.

[4] Luhong Zheng, Chengwen Chen, The Research of the Impact of Research Opportunity on the Cultivation of the Postgraduates' Creativity, Academic Degrees \& Graduate Education. 2(2008)20-27.

[5] Hongying Sun, Research on the Application of "Internet +" in Graduate Education, Journal of Graduate Education. 34(2016)55-59. 